\title{
Dynamics of Interleukin-2, Interleukin-6, Tumor Necrosis Factor Alpha Serum Levels and Interrelation of Cytokines in Patients with Liver Cirrhosis of Child- Pugh Classes A, B, C
}

\author{
Boris Fishman ${ }^{1 *}$, Vladimir Kulikov ${ }^{2}$, Mikhail Yukhno ${ }^{1}$, Zurabov V ${ }^{1}$, M Hapman ${ }^{2}$, T Tkachenko ${ }^{1}$, \\ 0 Azovceva ${ }^{1}$ and Yegor Rumyantsev ${ }^{1}$
}

${ }^{1}$ Institute of Medical Education, Yaroslav-the-Wize Novgorod State University, Russia

${ }^{2}$ Ulyanovsk State University, Russia

*Corresponding author: Boris Fishman, Institute of Medical Education, Yaroslav-the-Wize Novgorod State University, Veliky Novgorod, Russia

To Cite This Article: Boris F*, Vladimir K, Mikhail Y, Zurabov V, M Hapman, Holodkov BA, Mogelladze NO, et al., Dynamics of Interleukin-2, Interleukin-6, Tumor Necrosis Factor Alpha Serum Levels and Interrelation of Cytokines in Patients with Liver Cirrhosis of Child-Pugh Classes A, B, C. Am J Biomed Sci \& Res. 2019 - 1(4). AJBSR.MS.ID.000533. DOI: 10.34297/AJBSR.2019.01.000533

Received: February 14, 2019 | Published: February 22, 2019

\begin{abstract}
The research objectives were to determine serum interleukins (IL-2, IL-6) and tumor necrosis factor alpha (TNF- $\alpha$ ) and evaluate their interrelation in liver cirrhosis (class A, B, C according to Chad-Pugh). 117 patients were examined, and their cytokines levels were determined using enzyme-linked immunosorbent assay. Elevation of cytokine levels IL-2, IL-6 and TNF- $\alpha$ within reference values was found in liver cirrhosis cases, expect for level IL-6 in liver cirrhosis cases of class C. In these cases IL-6 level exceeds reference values and is within the limit of 9,94-25,21 pg/ml with average concentration of $14,89 \pm 4,96 \mathrm{pg} / \mathrm{ml}$. Correlation is found between TNF- $\alpha$ and IL- $6(\mathrm{r}=-0,499)$ in liver cirrhosis of class A and correlation between TNF- $\alpha$ and IL-2 $(r=0,421)$ is found in liver cirrhosis of class B.
\end{abstract}

Keywords: Interleukin-2; Interleukin-6; Tumor necrosis factor alpha; Liver cirrhosis

\section{Introduction}

Many clinical and experimental studies are devoted to the study of liver cirrhosis and its complications. Most frequent causes and predisposing factors of liver cirrhosis have been revealed. At the same time, many issues of the pathogenesis of complications of liver cirrhosis are still insufficiently studied, and the results of scientific research conducted in this field are contradictory. Peripheral vasodilatation theory is considered to be the most plausible for explaining the etiology of liver cirrhosis complications, but it does not answer all the existing questions on this issue [1,2].

At present, influence of cytokines on the activation of the pathological process in the liver and impaired portal blood flow have not been sufficiently studied [3-6]. In addition, there are data on the activation of the cytokine cascade in liver cirrhosis. Increased levels of tumor necrosis factor alpha and interleukin-6 causes liver damage and correlate with the severity of liver cirrhosis $[7,8]$. Given the heterogeneity of data in the literature concerning the serum level of cytokines and their influence, studies of the mechanisms of pathogenesis and complications in liver cirrhosis in this direction should continue. At the same time, there are no clear data on the interrelations of functional indices of the liver and the serum cytokine levels in liver cirrhosis [9,10].

\section{Materials and Research Methods}

The main findings of the work were obtained in a study of 117 patients with liver cirrhosis (LC) of viral etiology without inflammatory processes of organs and systems in the acute stage, increased hormone levels and arterial hypertension of grade 3 that accompany the main diagnosis. In the largest number of patients (n $=54(46.1 \%)$ ), the LC developed on the background of HCV infection, with HBV infection-in 41 (35.1\%) and mixed infection (HCV + HBV)in $22(18,8 \%)$ patients. LC developed mainly from 10 years or more 
from the time of diagnosis. The shortest period of LC development was observed in patients of mixed etiology (HBV + HCV infections), but at the same time it was not statistically significant $(p=0.079)$ in comparison with patients of other etiology. On average, the LC developed within $10.1 \pm 2.8$ years and occurred in all age periods of patients. LC more often developed in men $(\mathrm{n}=91(77.8 \%))$ than in women $(n=26(22.2 \%)$ and at a younger age in men in the age range $55.4 \pm 2.9$ years, in women- $62.3 \pm 3.5$ years. The average age of all patients was $57.3 \pm 4.6$ years.

The diagnosis of the disease with the verification and treatment was made in full accordance with the classification of WHO experts (Los Angeles, 1994) and the National Clinical Recommendations of the All-Russian Scientific Society of Gastroenterologists (2011). Based on the classification of the LC by Child-Pugh (1996), the patients were divided into 3 groups: Group I consisted of patients ( $\mathrm{n}=38$ ) Child-Pugh class A with TNF- $\alpha$ and IL-2, IL-6; Group IIpatients $(\mathrm{n}=40)$ Child-Pugh class B with TNF- $\alpha$ and IL-2, IL-6; Group III included patients $(\mathrm{n}=39)$ Child-Pugh class $\mathrm{C}$ with TNF- $\alpha$ and IL-2, IL-6.

The control group consisted of 30 healthy volunteers (blood donors). The definitions of the levels of interleukin-2 (IL-2), interleukin-6 (IL-6) and tumor necrosis factor alpha (TNF- $\alpha$ ) were based on the solid phase "sandwich" enzyme-linked immunosorbent assay (ELISA). To obtain results and dynamic observations that adequately reflect changes in the serum concentrations of IL-2, IL-6 and TNF- $\alpha$, reagent kits of the same name were used ("Interleukin2-ifa-best," Interleukin-6-ifa-best "and "TNF-alpha-ifa-best") and one of the same manufacturers (Nizhny Novgorod). Serum cytokine levels were measured from 9 to 11 o'clock.

Validation of results consisted of several stages. At the first stage, the classical method, based on the theory of sampling, was used to calculate the volume of the required statistical sample. The resulting statistical material was grouped into variational series, which were further analyzed for compliance with the distribution using descriptive statistics, the law of Gauss Laplace distribution. Nonparametric statistical methods based on Kendall's concordance and Friedman criteria were also used. Average values were used, the indicator $\mathrm{Me} \pm \mathrm{SD}$ was taken into account in the comparative analysis.

At the second stage of processing the statistical material obtained, data was grouped by variation series, taking into account the magnitude of the statistical significance of the results at $p$ $<0.05$. Gaussian density distribution was estimated from the values of the interquartile range. Using the Spearman correlation matrix method, the degree of interrelation between individual signs was determined. Statistical processing was carried out using Stat Soft Statistica, version 8.0 .

\section{Results and Discussion}

In patients with LC, depending on the stage of compensation, there is a general tendency for the serum levels of all cytokines to increase, but within the reference values, with the exception of IL-6 (Table 1). In class A LC, TNF- $\alpha$ ranged from $1.83-2.32 \mathrm{pg} / \mathrm{ml}$, $5.15-9.32 \mathrm{pg} / \mathrm{ml}, 1.23-3.15 \mathrm{pg} / \mathrm{ml}$ and averaged $2.02 \pm 0.17 \mathrm{pg} / \mathrm{ml}$, $6.47 \pm 0.91 \mathrm{pg} / \mathrm{ml}, 2.47 \pm 0.61 \mathrm{pg} / \mathrm{ml}$ respectively. In class B LC, the levels of IL-2, IL-6, TNF- $\alpha$ ranged from $1.02-9.35 \mathrm{pg} / \mathrm{ml}, 1.11-14.95$ $\mathrm{pg} / \mathrm{ml}, 1.78-3.11 \mathrm{pg} / \mathrm{ml}$ and on average amounted to $3.66 \pm 2.99 \mathrm{pg} /$ $\mathrm{ml}, 8.97 \pm 3.95 \mathrm{pg} / \mathrm{ml}, 2.62 \pm 0.47 \mathrm{pg} / \mathrm{ml}$, respectively. In patients with class C LC, the levels of IL-2, IL-6, TNF- $\alpha$ ranged from $1.04-8.39 \mathrm{pg} /$ $\mathrm{ml}, 9.94-25.21 \mathrm{pg} / \mathrm{ml}, 1.74-7.11 \mathrm{pg} / \mathrm{ml}$ and on average amounted to $3.99 \pm 2.41 \mathrm{pg} / \mathrm{ml}, 14.89 \pm 4.96 \mathrm{pg} / \mathrm{ml}, 3.96 \pm 1.82 \mathrm{pg} / \mathrm{ml}$ respectively. At class C LC, the limits of fluctuations of the mean IL- 6 values were higher than the reference values of the donors and were noted within $14.89 \pm 4.96 \mathrm{pg} / \mathrm{ml}$. It should also be noted that fluctuations in the levels of IL- 6 with class A LC were within the reference values, class B-in $42.5 \%$ of 40 patients, class C in only $30.8 \%$ of 39 patients. In other patients with classes B and C LC, the fluctuation levels of IL- 6 exceeded the reference values.

\begin{tabular}{|c|c|c|c|c|c|}
\hline Cytokines & $\mathbf{M} \div \mathbf{M}$ & Xmed & SD & Range & Gaussian density \\
\hline \multicolumn{6}{|c|}{ Patients with LC of Child-Pugh class A $(n=38)$} \\
\hline $\mathrm{IL}-2, \mathrm{pg} / \mathrm{ml}$ & $1,83-2,32$ & 1,94 & 0,17 & 0,49 & 0,34 \\
\hline $\mathrm{IL}-6, \mathrm{pg} / \mathrm{ml}$ & $5,15-9,32$ & 6,45 & 0,91 & 4,17 & 0,97 \\
\hline TNF- $\alpha, p g / m l$ & $1,23-3,15$ & 2,32 & 0,61 & 1,92 & 0,99 \\
\hline \multicolumn{6}{|c|}{ Patients with LC of Child-Pugh class B $(n=40)$} \\
\hline $\mathrm{IL}-2, \mathrm{pg} / \mathrm{ml}$ & $1,02-9,35$ & 2,12 & 2,99 & 8,34 & 5,52 \\
\hline $\mathrm{IL}-6, \mathrm{pg} / \mathrm{ml}$ & $1,11-14,95$ & 8,32 & 3,95 & 13,85 & 5,33 \\
\hline TNF- $\alpha, \mathrm{pg} / \mathrm{ml}$ & $1,78-3,11$ & 2,83 & 0,47 & 5,37 & 3,24 \\
\hline \multicolumn{6}{|c|}{ Patients with LC of Child-Pugh class C $(n=39)$} \\
\hline $\mathrm{IL}-2, \mathrm{pg} / \mathrm{ml}$ & $1,04-8,39$ & 2,46 & 2,41 & 7,35 & 4,27 \\
\hline $\mathrm{IL}-6, \mathrm{pg} / \mathrm{ml}$ & $9,94-25,21$ & 13,31 & 4,96 & 15,24 & 7,94 \\
\hline TNF- $\alpha, \mathrm{pg} / \mathrm{ml}$ & $1,74-7,11$ & 3,29 & 1,82 & 1,33 & 0,80 \\
\hline
\end{tabular}


In patients with class A LC, the values of interquartile ranges of the levels of IL-2, IL- 6 , TNF- $\alpha$ were $0.49,4.17,0.99$, medianswithin $1.94,6.45,2.83$, respectively. In patients with class B LC, the values of interquartile ranges for IL-2, IL-6, TNF- $\alpha$ were 8.34, $13.85,5.37$, medians-2.12, 9.22, 3.29, respectively. In patients with class $C$, the magnitude of the interquartile ranges of the levels of IL-2, IL-6, TNF- $\alpha$ were 7.35, 15.27, 1.33, medians $2.46,13.31,2.32$, respectively. In donors aged 20 to 60 years, the concentration fluctuation limits for IL-2 ranged from 0.1 to $9.7 \mathrm{pg} / \mathrm{ml}$, IL- 6 from 0.2 to $9.8 \mathrm{pg} / \mathrm{ml}$ and TNF- $\alpha$ from 0,1 to $4.7 \mathrm{pg} / \mathrm{ml}$, respectively (the levels obtained from donors are not statistically consistent with the manufacturer). By median, the serum level of cytokines in patients with LC is higher in comparison with donors.

Matrix correlation analysis of the interrelationships between cytokines in liver cirrhosis classes A, B, C (Table 2), showed that the most significant correlation interrelations were observed between tumor necrosis factor $\alpha$ and interleukin 6 in case of class A LC ( $\mathrm{r}=$ 0.499 ), tumor necrosis factor- $\alpha$ and interleukin-2 with class B LC $(\mathrm{r}=0.421)$.

Table 2: Matrix correlation analysis of the interrelations between cytokines in liver cirrhosis classes A,B,C.

\begin{tabular}{|c|c|c|c|c|c|c|c|c|c|}
\hline & IL-6 & IL $\neg 6$ & IL $\neg 6$ & TNF- $\alpha$ & TNF- $\alpha$ & TNF- $\alpha$ & IL $\neg 2$ & IL $\neg 2$ & IL $\neg 2$ \\
\hline & LC A & LC B & LC C & LC A & LC B & LC C & LC A & LC B & LC C \\
\hline IL $\neg 6$ & & \multirow{2}{*}{0,006} & \multirow{2}{*}{0,043} & \multirow{2}{*}{$-0,499$} & \multirow{2}{*}{$-0,175$} & \multirow{2}{*}{0,080} & \multirow{2}{*}{$-0,371$} & \multirow{2}{*}{$-0,112$} & \multirow{2}{*}{$-0,070$} \\
\hline LC A & & & & & & & & & \\
\hline IL $\neg 6$ & & & \multirow{2}{*}{$-0,072$} & \multirow{2}{*}{$-0,140$} & \multirow{2}{*}{$-0,007$} & \multirow{2}{*}{0,206} & \multirow{2}{*}{0,372} & \multirow{2}{*}{$-0,060$} & \multirow{2}{*}{$-0,237$} \\
\hline LC B & & & & & & & & & \\
\hline IL $\neg 6$ & & & & \multirow{2}{*}{$-0,155$} & \multirow{2}{*}{0,166} & \multirow{2}{*}{0,292} & \multirow{2}{*}{0,040} & \multirow{2}{*}{0,234} & \multirow{2}{*}{$-0,127$} \\
\hline LC C & & & & & & & & & \\
\hline TNF- $\alpha$ & & & & & \multirow{2}{*}{0,305} & \multirow{2}{*}{0,080} & \multirow{2}{*}{$-0,224$} & \multirow{2}{*}{$-0,098$} & \multirow{2}{*}{0,187} \\
\hline LC A & & & & & & & & & \\
\hline TNF- $\alpha$ & & & & & & \multirow{2}{*}{0,012} & \multirow{2}{*}{$-0,175$} & \multirow{2}{*}{0,421} & \multirow{2}{*}{$-0,371$} \\
\hline LC B & & & & & & & & & \\
\hline TNF- $\alpha$ & & & & & & & \multirow{2}{*}{0,109} & \multirow{2}{*}{$-0,023$} & \multirow{2}{*}{$-0,053$} \\
\hline LC C & & & & & & & & & \\
\hline $\mathrm{IL} \neg 2$ & & & & & & & & \multirow{2}{*}{$-0,060$} & -0991 \\
\hline LC A & & & & & & & & & $-0,091$ \\
\hline $\mathrm{IL} \neg 2$ & & & & & & & & & 0316 \\
\hline LC B & & & & & & & & & $-0,310$ \\
\hline IL $\neg 2$ & & & & & & & & & \\
\hline LC C & & & & & & & & - & \\
\hline
\end{tabular}

\section{Findings}

a. Against the background of a decrease in cirrhosis compensation, there is an increase in serum levels of IL 2, IL 6 and TNF $\alpha$ within reference values, except for the level of IL-6 in class C cirrhosis, ranging from 9.94 to $25.21 \mathrm{pg} / \mathrm{ml}$ with an average concentration of $14.89 \pm 4.96 \mathrm{pg} / \mathrm{ml}$.

b. Quantitative ratios and the degree of the relationship between cytokines are determined by compensation for cirrhosis. A significant correlation relationship is noted between TNF- $\alpha$ and IL-6 ( $r=0.499)$ in case of class A liver cirrhosis, between TNF- $\alpha$ and IL-2 $(r=0.421)$ in case of class B liver cirrhosis.

\section{References}

1. Ivashkin VT (2009) Complications of portal hypertension in liver cirrhosis. Russian Physiological Journal 10: 74-76.

2. Mirodzhanov GK (2012) Interleukin - 6 and nitric oxide in the pathogenesis of portal hypertension and decompensation of liver cirrhosis. Clinical Medicine 1: 47-53.
3. Fingers MA (2011) Pathological anatomy. Geotavr pp. 1206.

4. Sherlock Sh (1999) Diseases of the liver and biliary tract. Medicine pp. 115.

5. Chen TA (2011) Effect of intravenous albumin on endotoxin removal, cytokines, and nitric oxide production in patients with cirrhosis and spontaneous bacterial peritonitis. Scand J Gastroenterol 44(5): 619-625.

6. Iwakiri Y, Groszmann RJ (2010) The hyperdynamic circulation of chronic liver diseases: from the patient to the molecule. Hepatology 43(1): 122130.

7. Köksal AS (2009) Clinical features, serum interleukin-6, and interferongamma levels of 34 Turkish patients with hepatoportal sclerosis. Dig Dis Sci 52(12): 3494-3497.

8. La Villa G, Gentilini P (2008) Hemodynamic alterations in liver cirrhosis. Mol Aspects Med 29: 113-119.

9. Nagano T, Yamamoto K, Matsumoto S, Okamoto R, Tagashira M, et al. (2010) Cytokine profile in the liver of primary biliary cirrhosis. J Clin Immunol 10: 422-426.

10. Navasa MC (2009) Tumor necrosis factor and interleukin - 6 in spontaneous bacterial peritionitis in cirrhosis: relationship with the development of renal impairment and mortality. J Hepatol 27: 12261232. 